\title{
Bruce Cain, Democracy More or Less - America's Political Reform Quandary
}

New York, Cambridge University Press, 2015, 251 pages

\section{Vincent Michelot}

\section{OpenEdition \\ Journals}

Édition électronique

URL : https://journals.openedition.org/ideas/1762

DOI : 10.4000/ideas. 1762

ISSN : 1950-5701

Éditeur

Institut des Amériques

\section{Référence électronique}

Vincent Michelot, «Bruce Cain, Democracy More or Less - America's Political Reform Quandary », IdeAs

[En ligne], 8| 2016, mis en ligne le 20 décembre 2016, consulté le 18 octobre 2022. URL : http:// journals.openedition.org/ideas/1762 ; DOI : https://doi.org/10.4000/ideas.1762

Ce document a été généré automatiquement le 18 octobre 2022.

\section{(c) (i) (9)}

Creative Commons - Attribution - Pas d'Utilisation Commerciale - Pas de Modification 4.0 International - CC BY-NC-ND 4.0

https://creativecommons.org/licenses/by-nc-nd/4.0/ 


\title{
Bruce Cain, Democracy More or Less - America's Political Reform Quandary
}

\author{
New York, Cambridge University Press, 2015, 251 pages
}

\author{
Vincent Michelot
}

\section{RÉFÉRENCE}

Bruce Cain, Democracy More or Less - America's Political Reform Quandary, New York, Cambridge University Press, 2015, 251 pages

1 Au moment où les États-Unis portent à la présidence Donald Trump, à l'issue d'une élection marquée non seulement par un contraste saisissant entre d'un côté une courte victoire du candidat républicain dans le collège électoral et de l'autre un avantage de plus de 2,8 millions de voix pour Hillary Clinton dans les suffrages populaires mais aussi par une mainmise du Parti républicain sur les trois pouvoirs de l'État fédéral et une majorité d'États fédérés, en partie grâce aux fortes distorsions de la représentation qui sont inscrites dans le système électoral américain, la lecture de l'essai de Bruce Cain s'impose comme un puissant antidote aux emportements populistes et à la tentation de la réforme à chaud. Le professeur de science politique à Stanford, qui est aussi un acteur engagé puisqu'il a activement participé à différentes commissions de réforme, notamment dans les domaines du découpage électoral, du financement des campagnes dont il est aujourd'hui un de meilleurs experts aux États-Unis et de l'amélioration de l'administration des élections, part d'un constat très consensuel dans la communauté des politistes : le système politique américain est aujourd'hui très largement dysfonctionnel et les Américains montrent un degré de confiance très faible vis-à-vis à la fois de leurs élus et des processus démocratiques qui produisent les politiques publiques. En témoignent les titres sinistres et désespérants des ouvrages majeurs de la décennie sur le Congrès "cassé ", les partis affaiblis, une constitution dont Sanford Levinson affirme qu'elle est « antidémocratique » ou les termes de « corruption » ou de ploutocratie » pour décrire le système de financement des campagnes électorales. En 
témoigne aussi la prévalence de termes comme "gridlock» (la paralysie institutionnelle), "polarisation partisane » ou " désintermédiation » dans la littérature récente sur le corps politique comme grand corps malade. En témoignent enfin un taux de participation électorale assez faible en dehors des élections présidentielles, la captation et le détournement par des minorités agissantes très organisées de procédures destinées à améliorer la représentativité et donc la responsabilité des élus devant les électeurs, ce que Bruce Cain appelle "l'illusion de la souveraineté populaire", ou encore l'illusion de la transparence absolue des processus gouvernementaux qui mène à la paralysie de la puissance publique. La qualité première de Democracy More or Less vient de ce que l'essai est tout sauf une énième "jérémiade " sur la déliquescence du politique américain. Bruce Cain s'intéresse en effet à l'articulation américaine fondamentale du fédéralisme américain et explore la manière dont les États, ces « laboratoires de la démocratie » pour reprendre l'expression célèbre de Louis Brandeis, contribuent dans leurs pratiques politiques à l'affaiblissement et à la dé-légitimation $\mathrm{du}$ politique à l'échelle nationale ; il retrace aussi les origines historiques de cette démocratie moins que parfaite et les trouve très largement dans les effets inattendus d'un empilement anarchique et hétéroclite de réformes qu'il divise dans leur inspiration en trois traditions ou courants : "populiste ", "pluraliste » et "apolitique ». Bruce Cain avance dès lors sa thèse avec force : si les nombreuses réformes adoptées par les États ou par le Congrès des États-Unis à l'échelle fédérale n'ont pas eu les effets escomptés, voire ont produit des conséquences dommageables au système, c'est que les acteurs de la réforme ont privilégié les courants populistes ou apolitiques (la République des experts) au détriment d'un tradition pluraliste qui place au centre de ses stratégies réformistes ces médiateurs indispensables que sont les partis politiques, les groupes d'intérêts, les associations citoyennes ou encore les médias. Pour Bruce Cain, l'approche pluraliste est plus réaliste car elle ne repose pas sur le postulat d'un électeur capable de décider de tout grâce à son bulletin de vote, elle intègre de manière structurelle le principe de la délégation qui est au cœur de l'action publique et elle ne mésestime pas les dangers d'un dessaisissement par les experts de la gouvernance. Le réformisme pluraliste est aussi une voie médiane qui permet à la fois d'écarter le risque d'une approche strictement partisane qui enferme la réforme dans l'étau des avantages relatifs acquis par l'un ou l'autre des deux grands partis (Bruce Cain est particulièrement convaincant sur les réformes menées autour de la sécurisation de la légalité des scrutins par les Républicains, notamment par le biais des Voter ID Laws) et encourage à une inclusion réelle (et non factice) du plus grand nombre dans la décision politique.

2 Partant de ce parti-pris théorique, Bruce Cain explore successivement au long de neuf chapitres courts mais denses les questions de la transparence, des «paradoxes de la participation ", des cycles de la réforme, d'une "juste représentation», de l'éthique autour du lobbying et de la lutte contre la corruption et le "pantouflage » à l'américaine, à savoir la tristement célèbre revolving door, et enfin l'administration des élections par les États. Son approche va dans le grain fin du politique américain avec des études de cas fouillées, notamment sur le désastre annoncé que fut la loi McCainFeingold (un développement salvateur qui s'écarte intelligemment de l'analyse traditionnelle des contempteurs de l'arrêt Citizens United qui serait, selon eux, seul responsable de l'actuelle dérive du système de financement des campagnes) mais aussi sur la question cruciale des référendums d'initiative populaire et de leur détournement par des groupes d'intérêts conservateurs. Juriste tout autant que politiste dans sa 
démarche, Bruce Cain termine son ouvrage sur un terrain où peu d'universitaires s'aventurent : une série de propositions très concrètes de réforme dont le fil conducteur est le renforcement des médiateurs d'une démocratie marquée au sceau du pluralisme plutôt que du populisme, du pragmatisme institutionnel plutôt que de l'irénisme de la transparence ou des mirages de la participation citoyenne.

\section{AUTEURS}

\section{VINCENT MICHELOT}

Vincent Michelot est professeur des universités à Sciences Po Lyon où il enseigne la politique américaine. Spécialiste des élections et des rapports entre les pouvoirs de l'État aux Etats-Unis, il est l'auteur de Kennedy (Paris, Gallimard, 2013). vincent.michelot@sciencespo-lyon.fr 